\title{
Early findings in outbreak of haemolytic uraemic syndrome among young children caused by Shiga toxin-producing Escherichia coli, Romania, January to February 2016
}

E Peron ${ }^{123}$, A Zaharia ${ }^{34}$, LC Zota ${ }^{34}$, E Severi 5 , 0 Mårdh ${ }^{5}$, C Usein ${ }^{6}$, M Bălgrădean ${ }^{78}$, L Espinosa ${ }^{5}$, J Jansa ${ }^{5}$, G Scavia 9 , A

Rafila ${ }^{70}$, A Serban ${ }^{11}$, A Pistol 4

1. European Programme for Intervention Epidemiology Training (EPIET), European Centre for Disease Prevention and Control (ECDC), Stockholm, Sweden

2. Gastrointestinal, zoonosis and tropical diseases unit, Department of infectious diseases epidemiology, Robert Koch Institute, Berlin, Germany

3. These authors contributed equally to this article

4. National Center for Communicable Diseases Surveillance and Control, National Institute of Public Health, Bucharest, Romania

5. European Centre for Disease Prevention and Control (ECDC), Stockholm, Sweden

6. Cantacuzino National Institute of Research, Bucharest, Romania

7. University of Medicine and Pharmacy 'Carol Davila', Bucharest, Romania

8. Department of Nephrology and Dialysis, Children's Emergency Hospital 'M.S. Curie', Bucharest, Romania

9. EU Reference Laboratory for Escherichia coli, Istituto Superiore di Sanità (ISS), Rome, Italy

10. National Institute of Infectious Diseases 'Matei Bals', Bucharest, Romania

11. Ministry of Health, General Directorate of Medical Assistance and Public Health, Bucharest, Romania

\section{Correspondence: Emilie Johanna Peron (perone@rki.de)}

\section{Citation style for this article:}

Peron E, Zaharia A, Zota L, Severi E, Mårdh O, Usein C, Bălgrădean M, Espinosa L, Jansa J, Scavia G, Rafila A, Serban A, Pistol A. Early findings in outbreak of haemolytic uraemic syndrome among young children caused by Shiga toxin-producing Escherichia coli, Romania, January to February 2016 . Euro Surveill. 2016;21(11):pii=30170. DOI: http://dx.doi.org/10.2807/1560-7917.ES.2016.21.11.30170

As at 29 February 2016, 15 cases of haemolytic uraemic syndrome with onset between 25 January and 22 February were reported among children between five and 38 months in Romania, and three of them died. Cases were mostly from southern Romania. Six cases tested positive for Escherichia coli 026 by serology. Fruits, vegetables, meat and dairy products were among the possible common food exposures. Investigations are ongoing in Romania to control the outbreak.

On 9 and 10 February 2016, the National Institute of Public Health of Romania (NIPH) was alerted about 12 paediatric cases of haemolytic uraemic syndrome (HUS). The children, most of them under two years of age, were from Arges, Bucharest and Dolj districts and were all admitted to the Children's Emergency Hospital 'M.S. Curie', in Bucharest. All had initially presented with diarrhoea, some with bloody diarrhoea, with onset from 25 January to 9 February. The NIPH and the Romanian Ministry of Health formed an outbreak investigation team (OIT). On 18 February, experts from the European Centre for Disease Prevention and Control (ECDC) joined the OIT. On 20 and 26 February, three additional cases were reported, one from Bacau and two from Arges district. This communication describes the epidemiological and microbiological investigations as at 29 February 2016.

\section{Outbreak investigation}

In Romania, four regional hospitals (in Bucharest, Cluj, Iasi and Timisoara) are referral centres for management of HUS cases. To establish the baseline on number of HUS cases in Romania and to confirm the outbreak, we collected data on HUS admissions to these four hospitals between 2010 and 2015 in childrenunder five years of age. We performed a descriptive time-series analysis by plotting the monthly number of HUS cases by date of diagnosis from 2010 to 2016, a 12-month moving average, and minimum, maximum and mean values observed by month between 2010 and 2015 . We compared the number of diagnoses in January and February 2016 to the maximum monthly number of HUS diagnoses between 2010 and 2015 .

We collected microbiological results of tests performed at district hospitals on stool samples from HUS cases diagnosed in January and February 2016.

The National Reference Laboratory (NRL) from Cantacuzino Institute in Bucharest tested for stx (stx1 and stx2) and eae genes by PCR. Isolates were tested with $O$ antisera against the main STEC serogroups by slide agglutination.

Serum samples from 12 cases were sent to the Istituto Superiore di Sanità (ISS) in Rome, Italy to be tested for 


\section{FIGURE 1}

Distribution of haemolytic uraemic syndrome cases by month of diagnosis, Romania, January 2010 to February 2016

A.

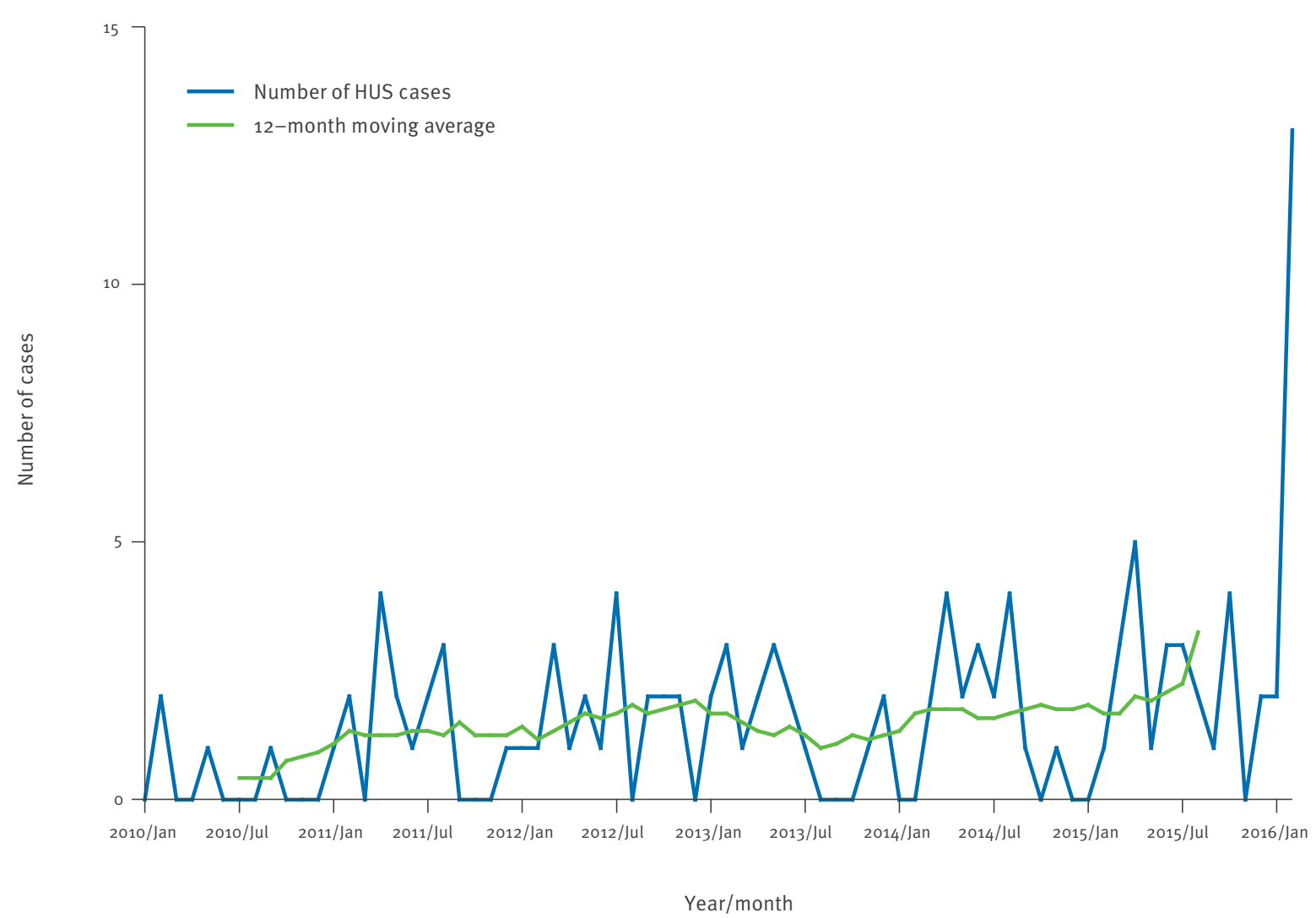

B.

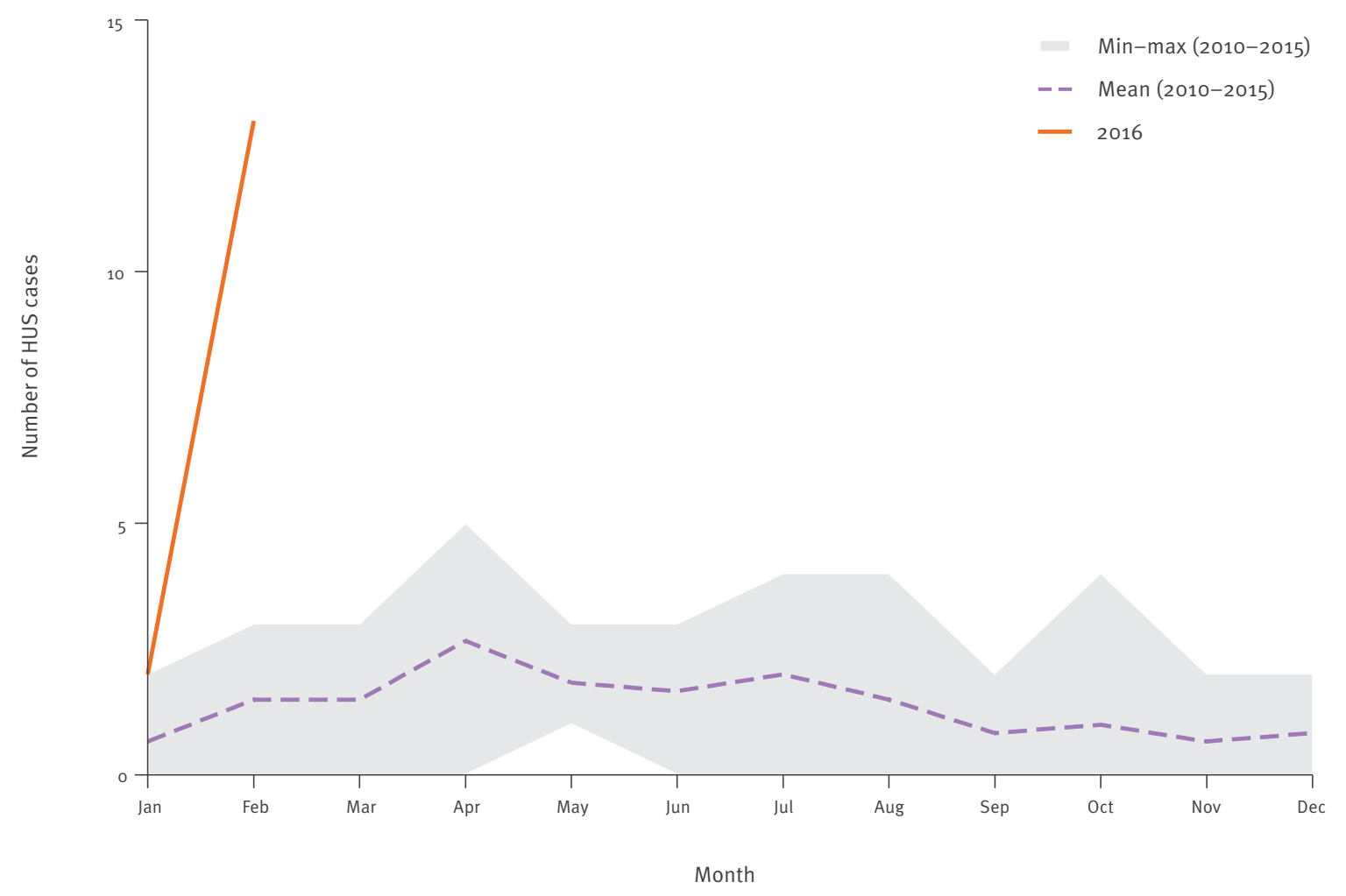

HUS: haemolytic uraemic syndrome. 
Geographical distribution of haemolytic uraemic syndrome outbreak cases by place of residence, Romania, 25 January to 22 February $2016(\mathrm{n}=15)$

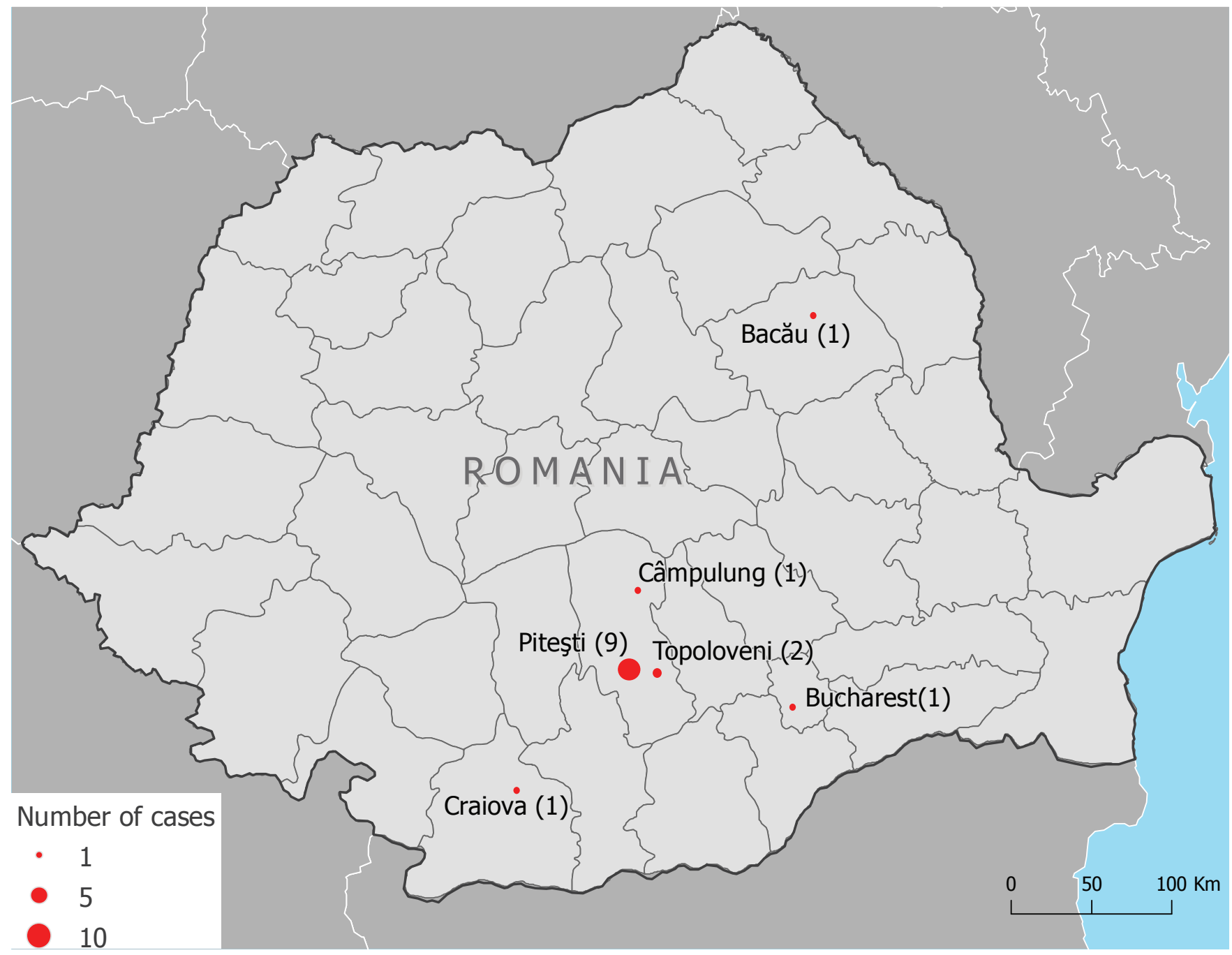

Source: European Centre for Disease Prevention and Control (ECDC).

antibodies to the lipopolysaccharide (LPS) of six major STEC serogroups $\left(\mathrm{O}_{157}, \mathrm{O}_{26} 6, \mathrm{O}_{103}, \mathrm{O}_{111}, \mathrm{O}_{145}\right.$, and 055) by ELISA [1].

For the purpose of this outbreak investigation, we formulated a case definition based on STEC laboratory confirmation, HUS diagnostic [2] and date of onset. A confirmed outbreak case was defined as any individual with onset of diarrhoea after 15 January 2016 in Romania and laboratory confirmation for STEC 026. A probable outbreak case was defined as any individual with onset of diarrhoea after 15 January 2016 in Romania, with clinical HUS but without laboratory confirmation for STEC 026 infection. Cases who travelled outside Romania within two weeks before symptom onset were excluded from the present investigation.

For active case-finding, a national HUS and severe diarrhoea surveillance system was set up on 15 February
2016. In addition, stool samples from 15 family members, all asymptomatic, of four confirmed and two probable cases were tested for Salmonella, Shigella, Yersinia, Campylobacter and E. coli (enteropathogenic $E$. coli, Shiga toxin-producing E. coli, enterotoxigenic $E$. coli and enteroinvasive E. coli).

To generate a hypothesis on the cause of the outbreak, between 24 and 28 February, parents or guardians of the cases were interviewed with a questionnaire that comprised questions on food and water exposures and activities during the 10 days before the symptom onset. The questionnaire also comprised questions regarding episodes of diarrhoea among family members.

\section{Findings}

Between 2010 and 2015, 101 HUS cases were diagnosed in Romania, with an average number of 16 cases per year, a minimum of five cases in 2010 and 
Distribution of haemolytic uraemic syndrome cases by date of diarrhoea onset, Romania, 25 January to 22 February 2016 $(\mathrm{n}=15)$

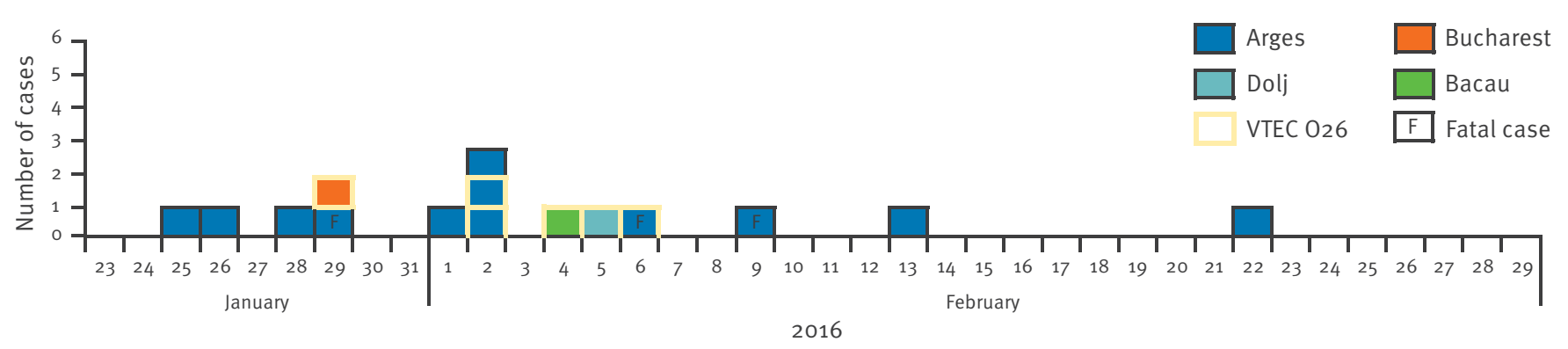

a maximum of 25 cases in 2015 . The descriptive timeseries analysis showed neither trend nor seasonality in the incidence of HUS from 2010 to 2016 (Figure 1a). As at 29 February 2016, 15 HUS cases were diagnosed in 2016: two in January and 13 in February. The number of cases diagnosed in February represented a 2.5-fold increase compared with the monthly maximum of five HUS diagnoses observed during the six previous years (Figure 1b).

Among the 15 cases identified in 2016, six were confirmed and nine were probable. They were aged between five and 38 months with a median age of 11 months. All but one were undertwo years of age. Nine children were female. Three cases died during this outbreak on 4, 15 and 16 February respectively.

Twelve cases (three confirmed, nine probable) resided in Arges district. The remaining three confirmed cases resided in Bucharest, Bacau and Dolj districts (Figure 2). The child from Bucharest spent the five days before onset in Bran (Brasov district, north-west of Arges) and this was considered the likely place of infection.

The date of onset of diarrhoea ranged from 25 January to 22 February (Figure 3).

Stool samples from three cases tested positive for enteropathogenic $E$. coli (EPEC) by agglutination using a polyvalent antisera at one district hospital laboratory. Because of poor quality, these specimens were not confirmed at the NRL.

Serum samples from 12 cases were sent to the ISS to be tested for $E$. coli 026 LPS antibodies. Six sera were positive: three cases were from Arges, the most affected district, and the remaining three cases were from Bucharest, Bacau and Dolj districts. One of these also tested positive for E. coli 0157 LPS antibodies. $\mathrm{NRL}$ isolated $E$. coli from one of the serologically confirmed case and identified the stx 2 toxin and the eae genes. Furthermore, two additional stool samples from cases in Arges were tested for stx 1 and 2 and eae, and both were positive; serogroup results are still pending.
All the stool samples from family members tested negative.

We interviewed parents or guardians of five confirmed and three probable cases and none of them mentioned episodes of diarrhoea among family members within the ten days before the disease onset of the child.

The food section of the interview showed that during the 10 days before their symptoms onset, the cases consumed: fresh fruits (apples (8/8), pears (6/8), oranges (7/8), bananas $(7 / 8)$ ), vegetables (roots $(8 / 8)$, pepper (8/8), zucchini (7/8)), meat (chicken ( $7 / 8)$, beef (4/8)), cow milk (4/8, unpasteurized for one of them), cow soft cheese (7/8; homemade for four of them) and yoghurt (6/8). All the other food items were consumed by less than four cases.

Fruits and vegetables were bought either from small local food producers or supermarkets with larger distribution, meat was supplied by family's own production or bought from supermarkets and dairy products were bought from several shops and were sometimes homemade. Two food chains were mentioned by parents/guardians during the interviews: one that distributed food only in Arges district (mentioned in relation to the consumption of soft cheese and yoghurt); and a second one that distributed food in the whole country, mentioned in relation to the consumption of oranges.

No other common exposure related to living conditions and outdoor activities could be identified.

\section{Discussion}

We describe a HUS outbreak with 15 cases, all among young children, of whom three died. The last case was reported on 26 February and had onset of symptoms four days before. Sera from six cases were positive for $E$. coli $\mathrm{O} 26$ antibodies, among which one was confirmed by slide agglutination from culture.

Since HUS usually occurs as a complication of STEC infection [3] in a small proportion of patients, we cannot exclude that further milder cases of STEC infection may have occurred in association with this outbreak 
even though no possible cases were identified in the investigation. Active case finding of HUS and severe diarrhoea is ongoing nationwide in Romania. As at 16 March, three additional confirmed and one probable case have been reported. These cases are from two districts previously not affected: Ialomita (two confirmed and one probable case) and Sibiu (one confirmed case) and had onset between 3 February and 4 March.

We hypothesise that this is a continuous common source food-borne outbreak, where most cases were infected by the same source over a four-week period. Different fresh food items may have been contaminated by the same source early in the food production chain and then distributed on the market over a prolonged period of more than a month.

Our study has several limitations. One is that we interviewed parents/guardians under a high emotional stress because this outbreak affected very young children and this may have led to lack of completeness of the clinical history. Moreover, due to incomplete characterisation of the strains, we may have included cases unrelated to this outbreak. Finally, for a number of cases infection may have occurred through personto-person transmission from a close contact, without being exposed to a contaminated food item.

Large STEC outbreaks, often associated with HUS cases, have been reported in several countries in the last decades [4-10]. Since 2010, the number of cases reported annually in The European Surveillance System (TESSy) [11] has steadily increased. The most frequent serotype is $\mathrm{O}_{157}$ and STEC $\mathrm{O}_{2} 6$ is the second most commonly reported serotype in the European Union (EU) ( 400 cases per year in TESSy). STEC 026 cases are generally younger than 0157 cases, have more severe diarrhoea, with more aggressive forms and higher proportion of the infected individuals develop HUS or other severe outcomes [12].

Outbreaks caused by STEC 026 have been associated in the past with unpasteurised milk and dairy products in Austria, Belgium and Italy [13-15].

A number of investigations are still ongoing in Romania to control this outbreak: environmental i.e. sampling food products in shops and from food producers, reviewing food production procedures of foods highlighted during the interviews; epidemiological i.e. collecting information through interviews with parents and or guardians of confirmed and probable cases but too few cases are currently available for an analytical study; active case finding i.e. surveillance for HUS in children (with reminders to front-line healthcare workers) and testing suspected cases for pathogenic $E$. coli; microbiological i.e. PFGE and whole genome sequencing to confirm outbreak cases and compare with isolates from foods (when available), and with previously reported 026 strains in TESSy.
On 4 March, during an environmental investigation undertaken following the information collected from the exploratory questionnaires, different cheese samples from a milk processing establishment in Arges district tested positive for stx genes. Isolates of $E$. coli 026 were identified in a soft cheese from the same establishment. On 5 March, this establishment voluntarily stopped production and closed the factory; the batches of suspected products were withdrawn from the Romanian market. The Romanian Food Safety Authority started an investigation tracing the distribution of the products from this milk processing establishment. On 7 March a Rapid Alert System for Food and Feed (RASFF) news (reference 16-811) was issued by the Romanian health authorities indicating that in 2016 products from this establishment were sold in other EU countries as well: Belgium, Germany, Italy and Spain. Furthermore, individual importations of products from the implicated establishment to other countries by individuals returning from Romania cannot be excluded.

This is a stark reminder that STEC can cause infections with severe complications, particularly among young children. Detection of outbreaks in the absence of sensitive and timely surveillance systems can be challenging, particularly if local laboratory capacities are not optimal. Improving local laboratories diagnostic capacities and performing unspecific HUS surveillance in children should be considered as a public health priority to avoid this from happening again. It is not yet clear when this outbreak started, and neither the vehicles nor the source of contamination were identified. However, after initial suspicion, the investigations confirmed the outbreak and its causative agent. This is an example of good collaboration between EU countries in terms of provision of laboratory services support and expert advice, and ECDC, in providing expert deployment and support.

\section{Acknowledgements}

We thank Alfredo Caprioli for the support provided during the investigation, Silviu Lucian Ionescu and Emmanuel Robesyn for the support in preparing the map, Joana Gomes Dias for her timely help in producing time series outputs and Johanna Takkinen, Marc Struelens, Denis Coulombier and Andrea Ammon for their support during the investigation.

\section{Conflict of interest}

None declared.

\section{Authors' contributions}

Emilie Peron, Alina Zaharia and Lavinia Cipriana Zota investigated the outbreak, collected and analysed the data. Emilie Peron spearheaded writing of the manuscript. Codruta Usein, Alexandru Rafila and Gaia Scavia performed all the microbiological tests. Mihaela Bălgrădean provided clinical data. Josep Jansa and Laura Espinosa supervised the investigation and provided remote support. Ettore Severi, Otilia 
Mårdh, Amalia Serban and Adriana Pistol coordinated the outbreak investigation.

\section{References}

1. Caprioli A, Luzzi I, Rosmini F, Resti C, Edefonti A, Perfumo $\mathrm{F}$, et al. Community-wide outbreak of hemolytic-uremic syndrome associated with non-0157 verocytotoxin-producing Escherichia coli. J Infect Dis. 1994;169(1):208-11. DOI: 10.1093/ infdis/169.1.208 PMID: 8277184

2. Jenssen GR, Hovland E, Bjerre A, Bangstad HJ, Nygard K, Vold L. Incidence and etiology of hemolytic-uremic syndrome in children in Norway, 1999-2008--a retrospective study of hospital records to assess the sensitivity of surveillance.BMC Infect Dis. 2014;14(1):265. DOI: 10.1186/1471-2334-14-265 PMID: 24884396

3. Tarr PI, Gordon CA, Chandler WL. Shiga-toxin-producing Escherichia coli and haemolytic uraemic syndrome.Lancet. 2005;365(9464):1073-86.PMID: 15781103

4. Doorduyn Y, de Jager CM, van der Zwaluw WK, Friesema IH, Heuvelink AE, de Boer E, et al. Shiga toxin-producing Escherichia coli (STEC) 0157 outbreak, The Netherlands, September-October 2005. Euro Surveill. 2006;11(7):182-5. PMID: 16966799

5. Askar M, Faber MS, Frank C, Bernard H, Gilsdorf A, Fruth A, et al. Update on the ongoing outbreak of haemolytic uraemic syndrome due to Shiga toxin-producing Escherichia coli (STEC) serotype 0104, Germany, May 2011. Euro Surveill. 2011;16(22):19883.PMID: 21663710

6. Rubino S, Cappuccinelli P, Kelvin DJ. Escherichia coli (STEC) serotype 0104 outbreak causing haemolytic syndrome (HUS) in Germany and France.J Infect Dev Ctries. 2011;5(6):437-40. DOI: 10.3855/jidc.2172 PMID: 21727641

7. Aldabe B, Delmas Y, Gault G, Vendrely B, Llanas B, Charron $M$, et al. Household transmission of haemolytic uraemic syndrome associated with Escherichia coli $\mathrm{O}_{104}: \mathrm{H}_{4}$, southwestern France, June 2011. Euro Surveill. 2011;16(31):19934. PMID: 21871216

8. Jenkins C, Dallman TJ, Launders N, Willis C, Byrne L, Jorgensen $\mathrm{F}$, et al. Public Health Investigation of Two Outbreaks of Shiga Toxin-Producing Escherichia coli 0157 Associated with Consumption of Watercress. Appl Environ Microbiol. 2015;81(12):3946-52. DOI: 10.1128/AEM.04188-14 PMID: 25841005

9. Centers for Disease Control and Prevention (CDC),. Outbreak of Escherichia coli $0_{104: \mathrm{H}_{4}}$ infections associated with sprout consumption - Europe and North America, May-July 2011. MMWR Morb Mortal Wkly Rep. 2013;62(50):1029-31.PMID: 24352067

10. Frank C, Milde-Busch A, Werber D. Results of surveillance for infections with Shiga toxin-producing Escherichia coli (STEC) of serotype 0104: $\mathrm{H}_{4}$ after the large outbreak in Germany, July to December 2011. Euro Surveill. 2014;19(14):20760. DOI: 10.2807/1560-7917.ES2014.19.14.20760 PMID: 24739983

11. European Centre for Disease Prevention and Control (ECDC). Annual epidemiological report. Food-and waterborne diseases and zoonoses. Stockholm: ECDC. 2014. Available from: http://ecdc.europa.eu/en/publications/Publications/foodwaterborne-diseases-annual-epidemiological-report-2014.pdf

12. Pollock KG, Bhojani S, Beattie TJ, Allison L, Hanson M, Locking ME, et al. Highly virulent Escherichia coli 026 , Scotland. Emerg Infect Dis. 2011;17(9):1777-9. DOI: 10.3201/ eid1709.110199 PMID: 21888827

13. Germinario CCA, Chironna M, Gallone MS, Tafuri S, Desiante F, Calabrese G, et al. Community-wide Outbreak of Haemolytic Uremic Syndrome Associated with Shiga Toxin 2-Producing Escherichia coli O26:H11 in Southern Italy, Summer 2013. Euro Surveill. 2016; (Forthcoming).

14. Allerberger F, Friedrich AW, Grif K, Dierich MP, Dornbusch HJ, Mache CJ, et al. Hemolytic-uremic syndrome associated with enterohemorrhagic Escherichia coli 026:H infection and consumption of unpasteurized cow's milk. Int J Infect Dis. 2003;7(1):42-5. DOI: 10.1016/S1201-9712(03)90041-5 PMID: 12718809

15. De Schrijver K, Buvens G, Possé B, Van den Branden D, Oosterlynck O, De Zutter L, et al. Outbreak of verocytotoxinproducing E. coli $\mathrm{O}_{145}$ and $\mathrm{O}_{2} 6$ infections associated with the consumption of ice cream produced at a farm, Belgium, 2007. Euro Surveill. 2008;13(7):8041.PMID: 18445416

\section{License and copyright}

This is an open-access article distributed under the terms of the Creative Commons Attribution (CC BY 4.0) Licence. You may share and adapt the material, but must give appropriate credit to the source, provide a link to the licence, and indicate if changes were made.

This article is copyright of the authors, 2016. 